\title{
Patient assessment of the quality of dental care services in a Nigerian hospital
}

\author{
Ezekiel Taiwo Adebayo, Bola Ayodele Adesina, Lilian Ejije Ahaji, Nurudeen Ayoola Hussein \\ Army Dental Centre, Military Hospital, Lagos, Nigeria
}

Correspondence: Ezekiel Taiwo Adebayo. Address: GPO Box 3338, Kaduna 800001, Nigeria. E-mail: taiwo_adebayo@yahoo.com

Received: April 8, 2014

Accepted: August 19, 2014

Online Published: September 17, 2014

DOI : $10.5430 /$ jha.v3n6p20

URL: http: //dx.doi.org/10.5430/jha.v3n6p20

\section{Abstract}

Dental care services are available in many urban communities worldwide where discerning and sophisticated clients expect quality care. Many available studies evaluated satisfaction rather than quality of dental care; others did not reveal the patients' perception of gaps in the quality of care. Service quality (SERVQUAL) tool assesses quality of service based on the dimensions of tangibles, reliability, responsiveness, assurance and empathy as described by Parasuraman et al. (1985). The aim of this study was to assess the gaps in quality of dental care in a Nigerian government owned dental clinic using an unweighted SERVQUAL tool to determine the difference between expectations and perceptions of patients. Consenting patients seen during the study period were given a 32-items questionnaire divided equally between expectations and perception of quality of dental care services received. Out of 112 questionnaires analysed, patients had the most expectation for neatness $(4.69 \pm 0.85)$ and least for pain free treatment $(3.76 \pm 1.16)$. Highest perception was for knowledgeable clinic staff $(4.34 \pm 0.71)$ while support to enable staff work well was the least perceived quality $(3.73 \pm$ $0.86)$. Overall, among the 5 dimensions of quality, there were marked statistically significant quality gaps in assurance $(p=.0001)$ and tangibles $(p=.0006)$. This study showed that patients in a Nigerian government-owned dental clinic, there is need for greater attention to be paid to assurance, tangibles and reliability dimensions of service quality to improve patient perceptions.

\section{Key words}

Quality gap, Dental care, Perception, Expectation

\section{Introduction}

Dental care services are relatively scarce and expensive. In many countries including Nigeria, dental care services are patronised more in the large urban centres than in the rural areas. Poorterman et al. believes that as consumers of health care, dental patients are sophisticated with increasing demand for accountability from care givers ${ }^{[1]}$. Generally, quality could be described as the degree to which the characteristics of a product, process or service satisfies established or obvious needs ${ }^{[1]}$. Achieving quality dental care is desirable for patients ${ }^{[2]}$.

Worldwide, despite its importance to patient satisfaction, studies of the quality of dental care services are uncommon ${ }^{[3]}$ and lack uniform criteria. This is notwithstanding the equitable right of all patients to affordable, accessible, high quality care. Studies of quality and patient satisfaction are useful as an indicator, to assist health organizations to quickly identify 
consumers likely to disenroll ${ }^{[4]}$, to identify which aspects of service need to be changed to improve patient satisfaction ${ }^{[5]}$, to effectively compare different healthcare programs or systems ${ }^{[6]}$ and in the evaluation of the quality of care ${ }^{[7,8]}$. Some workers have used patient satisfaction as a proxy for quality of dental care by using the Dental Satisfaction Questionnaire ${ }^{[9-11]}$. Others assessed only patient perception of care received ${ }^{[12,13]}$. These studies concluded that patients' satisfaction implied quality care. This interpretation has several challenges. Perception of quality of health care received is a subjective attitude relating to the health service but is not equivalent to satisfaction ${ }^{[14]}$. Cronin and Taylor have shown that service quality is antecedent to satisfaction ${ }^{[15]}$. While service quality and consumer satisfaction share some common features, Zeithaml and Bitner states that satisfaction is broader than service quality whose assessment focuses on the dimensions of service ${ }^{[16]}$.

Parasuraman et al. articulated five dimensions of service quality (SERVQUAL) as tangibles, reliability, responsiveness, assurance and empathy ${ }^{[14,17]}$. According to Newsome and Wright, the five issues that influence patient satisfaction with dental treatment are technical competence, interpersonal factors, convenience, costs and facilities ${ }^{[18]}$. They believe these are equivalent to the dimensions of service described by Parasuraman et al. ${ }^{[14,17]}$ but noted that the perception of these attributes by the patient is not the sole determinant of patient satisfaction. The SERVQUAL dimensions were modified by Babakus and Mangold who designed and validated a 15-items questionnaire for hospital use by evaluating expectations and perceptions to identify the quality gaps in each dimension ${ }^{[19]}$. In their contribution to the relationship between service quality and satisfaction, Cronin and Taylor postulated determination of service quality on the basis of performance, formulating the SERVPERF tool ${ }^{[15]}$. In a later paper, they re-emphasised that consumer satisfaction had greater influence on purchase intentions than service quality. They however agreed that performance minus expectation was inadequate for measuring service quality ${ }^{[20]}$. Therefore, expectations remain quite important in the perception of service quality. The consumers of dental care services do not behave exactly as consumers of banking, pest control and fast foods tested by Cronin and Taylor ${ }^{[15]}$, hence their results may not be directly applicable. In dental care, patient's expectations especially of the attitudes and communication skills of the dentists remained important for overall patient satisfaction ${ }^{[18,21]}$. According to Crow et al. the most important health services factor affecting satisfaction was the quality of doctor-patients interacttion ${ }^{[22]}$. We used the SERVQUAL tool to assess perception of the quality of dental services because despite some criticisms, its dimensions remain reliable and valid ${ }^{[23,24]}$.

Rad and others evaluated patients at an Iranian dental school clinic on the assumption that increasing quality of care would improve patient satisfaction thereby encouraging increasing oral health care ${ }^{[12]}$. They found that patients had high expectations of quality dental care and appreciated the infection control practises and the accessibility of the dental clinic. However, patients complained of long waiting times, insufficient number of nurses and inadequate supervision of attending clinicians ${ }^{[12]}$. The study did not quantify the degree of expectation or disapproval. It was therefore an inadequate measure of the quality of dental care services and its impact on encouraging patients to seek care.

Using a SERVQUAL-type questionnaire, Karydis et al. studied Greek patients finding significant quality gap based on the difference between perception and expectation ${ }^{[2]}$. The highest quality gaps were for responsiveness followed by empathy and reliability. The least gap was for assurance. In one of very few Nigerian reports, Oketade et al. ${ }^{[13]}$ evaluated patients attending a tertiary dental care facility in Nigeria. They found that most patients $(89.1 \%)$ ranked the clinicians ability to deliver painless dentistry as the most important clinician-determined criterion of good clinical practice. In their evaluation of patient- determined criteria, most patients $(85.1 \%)$ were concerned about sterility of procedures and proper handling of instruments. Oketade et al. ${ }^{[13]}$ evaluated perception only as a measure of quality rather than considering expectations to deduce the quality gap as described by Parasuraman et al. ${ }^{[14,17]}$. Expectations are future focused, while perceptions are "after the fact" ${ }^{[14,17]}$. These previous studies ${ }^{[12,13]}$ did not measure the degree to which quality of dental care had been evaluated as the "quality gap" essential to such rigour could not be evaluated by their study tools. In this study, the view of Parasuraman et al. ${ }^{[14,17]}$ that quality of a service such as dental care is best assessed by the "quality gap" obtained between patients' expectations and perceptions was utilised. The purpose was to report patient assessment of the degree of quality of dental care services provided in a typical Nigerian government-owned dental center with a view to recommending measures to improve dental care services. 


\section{Materials and methods}

Ethical clearance for the study was obtained from Nigerian Ministry of Defence Health Research Ethical Committee. Patients seen at the Army Dental Centre, Lagos between June and November 2013 were approached and those who consented to participate were recruited for the study. The dental centre offers all forms of outpatient dental treatment. Paediatric patients had parents fill the questionnaire for them. Each patient was self-administered 32-items questionnaire adapted from that of Babakus and Mangold ${ }^{[19]}$. The questionnaire was divided equally between expectations and perceptions of patients to determine the quality of dental care received based on dimensions of service proposed by Parasuraman et al. ${ }^{[14,17]}$.

Tangibles measured availability of modern dental equipment, visual appeal of the care facility, and neatness of employees. Under reliability, the tool measured workers fulfilment of treatment promised to patients, workers reassurance and confidence in handling patients and accuracy of billing. Responsiveness considered whether dental staff informed patients of the exact time of treatment, promptness of services and the willingness of clinic staff to help patients. In evaluating assurance, patients' feeling of safety, knowledge level of staff, politeness and employers support for employees work were measured. Empathy dealt with level of personal attention by dental staff to patients, belief that clinicians are working in the best interest of the patient and ability to control pain. Dimensions were assigned weights based on the number of questions as tangibles-3, reliability-3, responsiveness-3, assurance-4 and empathy-3. Each item was assessed on a 5-item Likert-type scale (1- Strongly disagree to 5- Strongly agree). Responses were entered into Microsoft Excel software and the quality gap between perception and expectation for each question was computed, and tested using 2-way Student $t$-test for dependent samples. Internal reliability of the scale (quality dimensions) was assessed by calculation of the Cronbach's $\alpha$. Statistical significance was set at $p \leq .05$.

\section{Results}

A total of 115 patients consented and filled the questionnaire, three questionnaire lacked sufficient demographic details and were discarded from analysis. Out of 112 questionnaire analysed, the age range was 6 to 70 years, mean 35.1 years \pm 14.4. There were 61 males and 51 females, giving a ratio of 1.2:1. Most were 26-35 years old (30.4\%), the least were 46-55 years old $(9.8 \%)$. On the basis of form of payment for dental services, more paid cash out of pocket $(\mathrm{n}=78,69.6 \%)$ than through health insurance $(n=34,30.4 \%)$. Most patients $(n=44,39.3 \%)$ were at the clinic for the first time while only few $(5.3 \%)$ were coming for the fifth or more time. Demographic details of 112 Nigerian patients analysed for quality of dental care is shown as Table 1.

Table 1. Demographic details of 112 Nigerian patients analysed for quality of dental care $(\mathrm{n}=112)$

\begin{tabular}{ll}
\hline Item & Number (\%) \\
\hline Gender & $61(54.5)$ \\
Male & $51(45.5)$ \\
Female & \\
Age groups & $12(10.7)$ \\
6-17years & $18(16.1)$ \\
18-25 years & $34(30.4)$ \\
26-35 years & $24(21.4)$ \\
$36-45$ years & $11(9.8)$ \\
$46-55$ years & $13(11.6)$ \\
$56+$ years & \\
Forms of payment & $78(69.6)$ \\
OOP & $34(30.4)$ \\
\hline NHIS* &
\end{tabular}


Table 1. (continued.)

\begin{tabular}{ll}
\hline Item & Number (\%) \\
\hline Number of attendance & $44(39.3)$ \\
$1^{\text {st }}$ & $26(23.2)$ \\
$2^{\text {nd }}$ & $31(27.7)$ \\
$3^{\text {rd }}$ & $5(4.5)$ \\
$4^{\text {th }}$ & $6(5.3)$ \\
$5+$ & \\
\hline
\end{tabular}

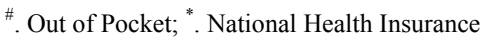

Cronbach's reliability analysis of the study questionnaire was carried out. Assurance had the highest reliability co-efficient of 0.826 , followed by reliability 0.671 and responsiveness 0.651 . The lowest reliability was for empathy 0.552 . Table 2 shows the reliability co-efficient of the various dimensions and assessment criteria for quality used in this study. Based on a 5 point Likert-type scale, patients had the highest expectation for neatness $(4.69 \pm 0.85)$ followed by the support from employers to employees $(4.60 \pm 0.78)$. The least expectation was for pain free treatment $(3.76 \pm 1.16)$. The expectation of patients in decreasing order is shown in Table 3. The best perceptions of patients were that the dental staffs are knowledgeable $(4.34 \pm 0.71)$ and neat $(4.32 \pm 0.71)$. There was low perception of the clinic in terms of giving patient personal attention $(3.90 \pm 0.86)$ and the support to staff to do their jobs well $(3.73 \pm 0.86)$. The perception of patients on the dental clinic in decreasing order is shown in Table 4.

Table 2. Reliability co-efficient with Cochrane's alpha

\begin{tabular}{lll}
\hline Item & $\mathbf{n}^{*}$ & $\mathbf{n}^{\#}$ \\
\hline Dimension & & \\
Tangibles & 0.599 & 0.881 \\
Reliability & 0.671 & 0.779 \\
Responsiveness & 0.651 & 0.905 \\
Assurance & 0.826 & 0.884 \\
Empathy & 0.552 & \\
Assessment & & \\
Expectations & 0.884 & 0.947 \\
Perceptions & 0.901 & 0.951 \\
\hline
\end{tabular}

" This study, ${ }^{\#}$ Australian study by Baldwin and Sohal (2003) using 22 items in 3 batteries. Assurance and empathy were assessed together.

Table 3. Expectations of patients of a dental clinic in decreasing order

\begin{tabular}{ll}
\hline Expectations Scale & Mean \pm SD \\
\hline 1. Clinic's employees should appear neat. & $4.69 \pm 0.85$ \\
2. This dental clinic staff should get adequate support from their employers to do their jobs well. & $4.60 \pm 0.78$ \\
3. The dental clinic staff should be knowledgeable. & $4.59 \pm 0.77$ \\
4. This dental clinic staff should be polite. & $4.58 \pm 0.73$ \\
5. Patients should be able to feel safe in their interactions with this dental clinic staff. & $4.56 \pm 0.81$ \\
6. Clinic employees should always be willing to help patients. & $4.53 \pm 0.72$ \\
7. It is realistic to expect clinic staff to have their patients' best interests at heart. & $4.43 \pm 0.76$ \\
8. This dental clinic should provide their services at the time they promise to do so. & $4.33 \pm 0.92$ \\
9. This dental clinic's workers should tell patients exactly when services will be performed. & $4.30 \pm 0.85$ \\
10. It is realistic for patients to expect prompt service from the dental clinic staff. & $4.24 \pm 0.85$ \\
11. This dental clinic should be accurate in their billing. & $4.23 \pm 0.88$ \\
12. When patients have problems, dental clinic workers should be sympathetic and reassuring. & $4.23 \pm 0.93$ \\
13. This dental clinic should have up-to-date equipment. & $4.22 \pm 0.93$ \\
14. This dental clinic's physical facilities should be visually appealing. & $4.22 \pm 0.79$ \\
15. This dental clinic's staff should be expected to give patients personal attention. & $4.07 \pm 1.00$ \\
16. It is expected that treatment would be pain free. & $3.76 \pm 1.16$ \\
\hline
\end{tabular}


Table 4. Perception of dental patients about quality in a dental clinic in decreasing order

\begin{tabular}{ll}
\hline Perception scale & Mean \pm SD \\
\hline 1. The clinic staff are knowledgeable. & $4.34 \pm 0.71$ \\
2. This dental clinic has neat looking staff. & $4.32 \pm 0.71$ \\
3. The staff did their best to make treatment pain free. & $4.31 \pm 0.77$ \\
4. The dental clinic staff are polite. & $4.31 \pm 0.82$ \\
5. This dental clinic staff are always willing to help patients. & $4.29 \pm 0.70$ \\
6. Patients feel safe in their interactions with dental clinic staff. & $4.20 \pm 0.84$ \\
7. When patients have problems, dental clinic staff are sympathetic and reassuring. & $4.17 \pm 0.75$ \\
8. The clinic has patients' best interests at heart. & $4.10 \pm 0.76$ \\
9. This dental clinic provides its services at the time it promises to do so. & $4.01 \pm 0.85$ \\
10. Patients receive prompt service from the dental clinic staff. & $3.99 \pm 0.82$ \\
11. The dental clinic staff tell patients exactly when services will be performed. & $3.99 \pm 0.93$ \\
12. This dental clinic's physical facilities are visually appealing. & $3.70 \pm 0.99$ \\
13. This dental clinic is accurate in its billing. & $3.69 \pm 0.88$ \\
14. This dental clinic has up-do-date equipment. & $3.61 \pm 1.08$ \\
15. The dental clinic staff gives patients personal attention. & $3.90 \pm 0.86$ \\
16. Employees get adequate support from the dental clinic to do their jobs well. & $3.73 \pm 0.86$
\end{tabular}

Generally, patient expectation statistically exceeded perception $(p=.002)$. The quality gap is the difference between perception and expectation scores for each study criterion. On the basis of dimensions of quality, assurance $(p=.0001)$ and tangibles $(p=.0006)$ had marked statistically significant gaps. Empathy had no statistically significant quality gap $(p=$ .756). The relative importance and quality gaps for each dimension of dental care is shown in Table 5. Cross tabulation of gender, number of visits and mode of payment revealed no statistically significant relationship to the dimensions of quality or quality gaps assessed in this study.

Table 5. The relative importance of the 5 dimensions of quality to dental patients in Lagos, Nigeria $(\mathrm{n}=112)$.

\begin{tabular}{lllll}
\hline & Expectation $($ mean $\pm \boldsymbol{S D})$ & Perception(mean $\pm \boldsymbol{S D})$ & Quality gap t $(\boldsymbol{t}$-test) & $\boldsymbol{p}$ level \\
\hline Tangibles & $4.30 \pm 0.86$ & $3.87 \pm 0.99$ & -4.68 & .000 \\
Reliability & $4.29 \pm 0.91$ & $3.95 \pm 0.85$ & -4.02 & .000 \\
Responsiveness & $4.35 \pm 0.81$ & $4.09 \pm 0.83$ & -3.13 & .002 \\
Assurance & $4.58 \pm 0.77$ & $4.15 \pm 0.85$ & -5.12 & .000 \\
Empathy & $4.08 \pm 1.03$ & $4.10 \pm 0.81$ & 0.312 & .756 \\
\hline
\end{tabular}

\section{Discussion}

In the United Kingdom and Denmark, it is known that more patients are now dentally aware and demanding of services that match their expectations ${ }^{[1,25]}$. Increased quality of dental care leads to improved patient satisfaction ${ }^{[1,15]}$. Groonros proposed that service quality has 2 distinct aspects the technical and the functional. In the field of health care, while technical quality focuses on the technical accuracy of the diagnosis and procedures, the functional quality is the manner in which the care is provided ${ }^{[26]}$. In the context of health care however, consumers (patients and their relations) have difficulty evaluating the technical quality, hence they assess service quality based on functional aspects alone ${ }^{[26]}$. Peterson stated that the patients' opinion of service quality was more important than that of health care practitioners ${ }^{[27]}$.

The various factors under each quality dimensions in our SERVQUAL-type questionnaire were analysed for internal consistency using Cronbach's $\alpha$ for reliability. Hair et al. state that Cronbach's $\alpha$ which varies from 0 to 1 has to be above 0.70 to be acceptable ${ }^{[28]}$. Baldwin and Sohal ${ }^{[24]}$ had higher Cronbach's $\alpha$ for their SERVQUAL-type questionnaire than 
our result as shown in Table 2. The better reliability of Baldwin and Sohal ${ }^{[24]}$ is likely from the higher number of questions on each scale as Cronbach's $\alpha$ has a positive relationship to the number of items on the scale ${ }^{[29]}$. They utilized 22 questions each for expectations and perceptions while this study had 16 questions for each part. Our overall reliability for expectation and perceptions is quite satisfactory as it exceeded the 0.70 threshold set by Hair et al. ${ }^{[28]}$ meaning our assessment of quality gap was valid.

Karydis et al. ${ }^{[2]}$ using the SERVQUAL-type tool to study Greek dental patients found that they had high expectations for adherence to the rules of antisepsis and sterilisation (mean $9.87 \pm 0.52$ out of 10) followed by the expectation of use of gloves (mean $9.71 \pm 0.98$ ). This is similar to the highest expectation in this study shown in Table 3 as need for dental clinic staff to appear neat (mean $4.69 \pm 0.85$ out of 5), followed by the need for staff to have adequate support from their employers (mean $4.60 \pm 0.78$ out of 5). Dental patients generally worry about communicable diseases such as HIV and hepatitis and expect dental staff to be neat and adhere to rules of antisepsis and sterilisation. In their perception, Greek dental patients were almost completely satisfied with adherence to rules of antisepsis and sterilization (mean $8.79 \pm 1.08$ out of 10), feeling of security within the clinic, tranquility and punctuality in appointment (mean $6.37 \pm 2.92$ out of 10) and the careful, scrupulous examination by the dentist (mean $6.12 \pm 3.22$ ). In Table 4, our patients had the highest perception for knowledge exhibited by the dental staff (mean $4.34 \pm 0.71$ out of 5), the neatness of staff (mean $4.32 \pm 0.71$ out of 5) and ability to render pain free treatment (mean $4.31 \pm 0.77$ ). While most dental patients cannot assess technical acumen of dental clinic staff, patients appreciate when staff are knowledgeable and provide pain free treatment. Dewi et al. has analysed dental patients in West Java, Indonesia using a SERVQUAL-type questionnaire ${ }^{[29]}$. Patients' satisfaction with treatment had the best relationship to response given by administrative staff to long waiting times ( $t$-test 5.377), knowledge level of dental assistant ( $t$-test 4.822) and explanation given by the dentist ( $t$-test 4.700$)^{[29]}$.

Among 481 Malaysian dental outpatients, John et al. ${ }^{[30]}$ found that responsiveness; assurance and empathy were the important determinants of quality. Table 5 showed that our dental patients had the widest quality gap for tangibles, reliability and assurance $(p=.000)$. The least gap was for empathy $(p=.756)$. Our results contrast these previous reports. It could be that Nigerian patients were more focused on the environment in which services are rendered (tangibles) than the compassionate and emotional aspects found in other cultures. These could reflect the generally poor infrastructure available in government health facilities in Nigeria such as this dental clinic. To improve patients' perception of dental care services, the Nigerian government needs to invest more funds in upgrading the infrastructure, equipment and instruments used to deliver dental care. According to Sbaraini et al. ${ }^{[31]}$, outpatient dental care services differs from other outpatient health care services because its focused on provision of tangible treatments such as the procedures performed in the mouth of patients at the dental clinic, need for follow-up visits for other physical interventions. This is in contrast to a visit to a doctor where the patient's focus might be receiving health advice, routine exams and/or drug prescriptions ${ }^{[31]}$.

The next widest gap in quality dimension was for reliability dealing with promptness of services, accuracy in billing and reassurance of patients by clinic staff (see Table 5). Regardless of procedure, patients are very appreciative of prompt service delivery and reassuring care through friendly discussion with patients on their care. Nigerian dental staff will need better interpersonal skills to improve service quality.

Though more patients paid cash (69.6\%) than accessed care through National Health Insurance (30.4\%) in Table 1, cost was the least satisfying aspect of dental care in another Nigerian report ${ }^{[11]}$. In our analysis, gender, mode of payment and frequency of dental visit had no statistically significant relationship to the quality gaps analysed. In the report by Karydis et $a l$. from Greece, women of the middle to lower socio-economic groups were more demanding than men of the same group while men of the upper socio-economic group were more demanding than women of the same group ${ }^{[2]}$. Socio-economic groupings were however, not analysed in our study. Cho et al. analysed the level of satisfaction of patients attending a South Korean health centre. They found that the average satisfaction for first time visitors was 5.25, second timer visitors was 5.04 while third timers had satisfaction level of 5.30 (1-very dissatisfied; 7-very satisfied). Using post-hoc comparison tests, the second time visitors were shown to be significantly less satisfied than the third time visitors. The first and third 
time visitors had no significant difference in satisfaction levels ${ }^{[32]}$. The broader construct of satisfaction over quality could explain the absence of relationship between the number of visits; mode of payment and gender with assessment of quality gaps observed in our study.

This study used a validated SERVQUAL-type questionnaire to evaluate expectations and perceptions revealing statistically significant gaps in the dimensions of assurance, tangibles and reliability (see Table 5). Our study indicates the need for better patient handling techniques by dental healthcare staff, improvement in the clinic infrastructure and increased professionalism through timeliness by dental personnel. This is similar to the previous report by Camilleri and O'Callaghan ${ }^{[33]}$ who evaluated Maltese public and private hospitals using a similar study instrument as ours. They found that three most significant service quality indicators in the opinion of patients were related to the hospital environment, personalised service and professional care.

Our analysis that Nigerian dental patients had more expectations than they perceived were been delivered could be a better measure of quality of dental care services than previous studies. While previous Nigerian studies used satisfaction as a proxy for quality ${ }^{[10,11]}$, our study revealed quality gaps unlike the study by Oketade et al. ${ }^{[13]}$ that considered perceptions without evaluating patients' expectations. Nigerian regulators of health care services should emphasise the qualities of assurance, tangibles and reliability during the training of dental care workers and supervision of all dental institutions. Our study has some limitations in applicability. In their assessment of the usefulness of SERVQUAL as a tool for assessing service quality perceptions among Greek patients attending primary health centres, Papanikolaou and Zygiaris observed the need for improvement in the definition of service quality beyond the simple expectation-perception gap as used in SERVQUAL-type studies such as ours. They believed that the gap is inadequate for evaluation of individual differences that could influence perception ${ }^{[34]}$. Further work is necessary to improve the understanding of the dimensions of quality applicable in health care especially in dental care services as there is presently no universally applicable tool. Cho et al. ${ }^{[32]}$ established a causal relationship between service quality as measured using SERVQUAL and satisfaction based on extensive assessment of South Korean patients attending a health centre. Another limitation was that it was conducted in a government-owned facility; hence it may not reflect the views of Nigerian patients attending privatelyowned dental clinics. It is however likely that in developing countries such as Nigeria more patients patronise governmentowned than privately-owned dental clinics. Hence, our results would reflect the view of majority of Nigerian dental patients.

\section{Conclusion}

There are few reports on the assessment of the quality of dental care services from developing countries such as Nigeria. Some available studies have used patient satisfaction to evaluate quality. There is general agreement that patients deserve more than the present level of care received from dental clinics. This study of a government- owned dental care facility revealed that more patients still pay for dental treatment out of pocket constituting financial burden on them. This could limit care-seeking behaviour on the basis of cost. Also significant quality gaps in the dimensions of assurance, tangibles and reliability of dental care services were recorded. The need for improved patient care and dental infrastructure complimented by increased health insurance coverage for dental care is stressed.

\section{Acknowledgements}

The contributions of staff of the Army Dental Centre, Military Hospital, Ikoyi, Lagos in data collection for this study are acknowledged. The views expressed in this paper are entirely those of the authors, they do not represent that of any Ministry, agency or department of any government in Nigeria. 


\section{References}

[1] Poortermann JHG, Van Weert CM, Eijkman MAJ. Quality assurance in dentistry: the Dutch approach. Int J Qual Health Care. 1998; 10(4): 345-350. http://dx.doi.org/10.1093/intqhe/10.4.345

[2] Karydis A, Komboli-Kodovazeniti M, Hatzigeorgiou D, Panis V. Expectations and Perceptions of Greek patients regarding the quality of dental health care. Int J Qual Health Care. 2001; 13(5): 409-416. PMid: 11669569.

http://dx.doi.org/10.1093/intqhe/13.5.409

[3] Laslett, A-M. Patient satisfaction among users of the Royal Dental Hospital of Melbourne, Research Report submitted in partial fulfilment of the requirement for the Master of Public Health, Department of Social and Preventative Medicine, Monash University, Melbourne. 1994.

[4] Weiss B, Senf H. Patient Satisfaction Survey Instrument for Use in Health Maintenance Organizations. Medical Cure. 1990; 28(5): 434-444. http://dx.doi.org/10.1097/00005650-199005000-00003

[5] Jackson L, Kroenke K. Patient satisfaction and quality of care. Military Medicine. 1997; 162: 273-277. PMid: 9110554.

[6] Andaleeb S. Service quality perceptions and patient satisfaction: a study of hospitals in a developing country. Soc Sci Med. 2001; 52: 1359-1370. http://dx.doi.org/10.1016/S0277-9536(00)00235-5

[7] Rubin G, George A, Chinn D, Richardson C. Errors in general practice: Development of an error classification and pilot study of a method for detecting errors. BMJ. 2003; 12: 443-447.

[8] Badri, M, Dodeen, H, Al Khaili M, Abdulla M. Development of the national inpatient satisfaction constructs and items for the United Arab Emirates. Int J Appl Health Studies. 2005; 1(3): 1-22.

[9] Chaffin JG, Moss D, Brehm B. Patient satisfaction in US Army Dental treatment facilities. Army Medical Department Journal. 2006 Jan-Mar; 10-15.

[10] Orenuga OO, Sofola OO, Uti OO. Patient satisfaction: A survey of dental outpatients at the Lagos University Teaching Hospital, Nigeria. Nig Qt J Hosp Med. 2009; 19(1): 47-52. PMid: 20830987.

[11] Adeniyi AA, Adegbite KO, Braimoh MO, Ogunbanjo BO. Factors affecting patient satisfaction at the Lagos State University Teaching Hospital Dental Clinic. Afr J Med Med Sci. 2013; 42(1): 25-31. PMid: 23909091.

[12] Rad M, Haghani J, Shahravan A, Khosravifar A. Qualitative assessment of the dental health services provided at a dental school in Kerman, Iran. Braz Oral Res. 2009; 23(4): 377-80. PMid: 20027443. http://dx.doi.org/10.1590/S1806-83242009000400005

[13] Oketade IO, Osiro O, Ibiyemi ST, Ibiyemi O. Perception of patients attending a tertiary hospital in Nigeria about good dental practice: A pilot study. Nig J Clin Prac. 2013; 16(4): 478-482. PMid: 23974743. http://dx.doi.org/10.4103/1119-3077.116893

[14] Parasuraman A, Zeithaml VA, Berry LL. SERVQUAL: A multiple-item scale for measuring customer perception quality. Journal of Retailing. 1988; 64(1): 12-40.

[15] Cronin JJ, Taylor SA. Measuring service quality: a re-examination and extension. Journal of Marketing. 1992; 56(July): 55-68. http://dx.doi.org/10.2307/1252296

[16] Zeithaml VA, Bitner MJ. Services marketing. New York; McGraw Hill. 2008. PMid: 18797449.

[17] Parasuraman A, Zeithaml VA, Berry LL. A conceptual model of service quality and its implications for futuring research. Journal of Marketing. 1985; 49: 41-50. http://dx.doi.org/10.2307/1251430

[18] Newsome PRH, Wright GH. A review of patient satisfaction: 2. Dental patient satisfaction, an appraisal of recent literature. Br Dent J. 1999; 186(4): 166-170. PMid: 10205952.

[19] Babakus E, Mangold WG. Adapting the SERVQUAL Scale to Hospital Services: An Empirical Investigation. Health Services Research. 1992; 26(6): 767-786. PMid: 1737708.

[20] Cronin JJ, Taylor SA. SERVPERF versus SERVQUAL: Reconciling performance-based and perception-minus-expectations measurement of service quality. Journal of Marketing. 1994; 56(Jan): 125-131. http://dx.doi.org/10.2307/1252256

[21] Fox C. Evidence summary: what do we know from qualitative research about people's care-seeking about oral health? Br Dent J. 2010; 209: 225-231. PMid: 20829863. http://dx.doi.org/10.1038/sj.bdj.2010.796

[22] Crow R, Gage H, Hampson S, Kimber A, Storey L, et al. The measurement of satisfaction with healthcare: implications for practice from a systematic review of the literature. Health Technol Assess. 2002; 6: 32.

[23] Carman JM. Consumer perceptions of service quality: an assessment of the SERVQUAL dimensions. Journal of Retailing. 1990; 66: 33-35.

[24] Baldwin A, Sohal A. Service quality factors and outcomes in dental care. Managing Service Quality. 2003; $13(3): 207-216$. http://dx.doi.org/10.1108/09604520310476472

[25] Tickle M, Whitehall R, Williams M. Health authorities, GDPs and TECs: a partnership for general dental practice development. Br Dent J. 1998; 185: 338-340. PMid: 9807917. http://dx.doi.org/10.1038/sj.bdj.4809810 
[26] Gronroos C. A service quality model and its marketing implications. Eur J Market. 1984; 18: 36-44. http://dx.doi.org/10.1108/EUM0000000004784

[27] Peterson MBH. Measuring patient satisfaction: collecting useful data. J Nurs Qual Assurance. 1988; 2: 25-35.

[28] Hair JF, Anderson RE, Tatham RL, Black WC. Multivariate Data Analysis, Prentice-Hall, Upper Saddle River. NJ. 1988.

[29] Dewi FD, Sudjana G, Oesman YM. Patient satisfaction analysis on service quality of dental health care based on empathy and responsiveness. Dent Res J (Isfahan). 2011; 8(4): 172-177. PMid: 22135687. http://dx.doi.org/10.4103/1735-3327.86032

[30] John J, Yatim FM, Mani SA. Measuring service quality of public dental health care facilities in Kelantan, Malaysia. Asia Pac Public health. 2011; 23(15): 742-53. PMid: 20460281. http://dx.doi.org/10.1177/1010539509357341

[31] Sbaraini A, Carter SM, Evans RW, Blinkhorn A. Experiences of dental care: what do patients value? BMC Health Services Research. 2012; 12: 177. PMid: 22726888. http://dx.doi.org/10.1186/1472-6963-12-177

[32] Cho WH, Lee H, Kim C, Lee S, Choi K-S. The impact of visit frequency on the relationship between service quality and outpatient satisfaction: A South Korean study. Health Services Res. 2004; 39(1): 13-33. PMid: 14965075. http://dx.doi.org/10.1111/j.1475-6773.2004.00213.x

[33] Camilleri D., O'Callaghan M. Comparing public and private hospital care service quality. Int J Health Care Qual Assurance. 1998; 11(4): 127-33. http://dx.doi.org/10.1108/09526869810216052

[34] Papanikolaou V, Zygiaris S. Service quality perceptions in primary health centres in Greece. Health Expectation. 2014; 17(2): 197-207. PMid: 22296402. http://dx.doi.org/10.1111/j.1369-7625.2011.00747.x 